\title{
A comparative case study of MTInSAR approaches for deformation monitoring of the cultural landscape of the Shanhaiguan section of the Great Wall
}

\author{
Hang $\mathrm{Xu}^{1,3}$, Fulong Chen ${ }^{1,2^{*}}$ and Wei Zhou ${ }^{1,2}$
}

\begin{abstract}
The Great Wall of China is one of the largest architectural heritage sites globally, and its sustainability is a significant concern. However, its large extent and diverse characteristics are challenges for deformation monitoring. In this study, the Shanhaiguan section of the Great Wall was investigated in a case study to ascertain the damage and potential hazards of the architectural site. Two standard multi-temporal synthetic aperture radar interferometry (MTInSAR) technologies, including persistent scatterer SAR interferometry (PSInSAR) and small baseline subset (SBAS) SAR interferometry, were used for deformation monitoring using high-resolution TerraSAR-X data acquired in 2015-2017. The results of the two MTInSAR approaches reveal the health condition of the Great Wall. The Shanhaiguan section was stable, but local instabilities caused by rock falls were detected in some mountainous areas. In addition, the applicability of PSInSAR and SBAS was evaluated. The performance analysis of the two approaches indicated that a more reliable and adaptable MTInSAR technique needs to be developed for monitoring the Great Wall. This study demonstrates the potential of MTInSAR technology with high-resolution data for the health diagnosis of heritage sites with a linear structure, such as the Great Wall.
\end{abstract}

Keywords: MTInSAR, Architectural heritage, Sustainability, The Great Wall, Shanhaiguan

\section{Introduction}

The Great Wall is one of the largest and oldest monuments globally and was designated a world cultural heritage site in 1987 due to its irreplaceable cultural and historical value [1]. The Great Wall was constructed intermittently for more than 2000 years from the Warring States period to the Qing Dynasty. It has a length of more than $21,000 \mathrm{~km}[2]$, passing through more than ten provinces in China and spanning different geomorphic units, such as mountains, valleys, deserts, and grasslands. However, under the long-term influence of natural erosion

\footnotetext{
*Correspondence: chenfl@aircas.ac.cn

${ }^{1}$ Key Laboratory of Digital Earth Science, Aerospace Information Research

Institute, Chinese Academy of Sciences, Beijing 100094, China

Full list of author information is available at the end of the article
}

and human activities, the current health condition of the Great Wall is not good [3-5]. In addition, there is spatial heterogeneity in the condition of the Great Wall due to different construction materials and driving forces [6]. Thus, a global monitoring method that can provide detailed information over large areas is essential for the health assessment and stability monitoring of the Great Wall.

Deformation is an important indicator of the monuments' stability [6]. However, the linear structure and the large extent of the Great Wall challenge traditional deformation monitoring methods, such as on-site visual inspection and fixed sensor deployment. Visual inspection $[7,8]$ is labor-consuming and may be dangerous for staff in desolate regions. For a fixed sensor-based method $[9,10]$, many sensors are required for large-area
Springer Open

(c) The Author(s) 2021. This article is licensed under a Creative Commons Attribution 4.0 International License, which permits use, sharing adaptation, distribution and reproduction in any medium or format, as long as you give appropriate credit to the original author(s) and the source, provide a link to the Creative Commons licence, and indicate if changes were made. The images or other third party material in this article are included in the article's Creative Commons licence, unless indicated otherwise in a credit line to the material. If material is not included in the article's Creative Commons licence and your intended use is not permitted by statutory regulation or exceeds the permitted use, you will need to obtain permission directly from the copyright holder. To view a copy of this licence, visit http://creativeco mmons.org/licenses/by/4.0/. The Creative Commons Public Domain Dedication waiver (http://creativecommons.org/publicdomain/ zero/1.0/) applies to the data made available in this article, unless otherwise stated in a credit line to the data. 
deformation monitoring, and they are difficult to maintain and may not be appropriate for a heritage site. Spaceborne remote sensing uses satellite observation and can obtain large-scale ground information; this technology is non-destructive and efficient for data acquisition [11-13]. As an active remote sensing technology, spaceborne synthetic aperture radar (SAR) provides all-time and all-weather ground surface information using microwaves. Synthetic aperture radar interferometry (InSAR) uses phase information to monitor ground deformation with millimeter accuracy [14-16] and has been widely used for monitoring landslides, urban surface subsidence, and infrastructure deformation [1720]. InSAR deformation products can cover large-area heritage sites and identify local deformation anomalies of a single building [12, 21]; thus, InSAR could be an effective method for the prevention and damage diagnosis of heritage sites.

In the past decade, InSAR has been widely applied for the deformation monitoring of cultural heritages, including the Olympia site in Greece [22], the Church of San Romolo in Italy [23], and the Angkor Wat in Cambodia [12]. In addition, a project named PROTIGO was proposed in 2016, aiming to apply InSAR technology for the safeguarding of more than 400 world cultural heritage sites in Europe [24]. However, the suitability of InSAR for stability monitoring of large heritage sites has not been investigated sufficiently. Thus, in this study, the Shanhaiguan section of the Great Wall was selected to assess and compare the performances of two standard multi-temporal InSAR (MTInSAR) algorithms, i.e., persistent scatterer SAR interferometry (PSInSAR) and small baseline subset (SBAS) for monitoring deformation anomalies. This study shows the potential and limitations of InSAR technology for the stability assessment of large linear cultural heritage sites, such as the Great Wall, laying a foundation for follow-up studies.

The rest of this paper is organized as follows. The study site and data usage are described in "Study site and data" Section, and the methodology and data processing are presented in "Methodology and data processing" Section. The validation of the InSAR results is described in "Cross-validation" Section, followed by the experimental results and interpretation in "Results and interpretation" Section. "Discussion" Section provides the discussion, and the conclusions are drawn in "Conclusion and prospect" Section.

\section{Study site and data Study site}

Shanhaiguan is located in the northeast of Qinhuangdao city, Hebei province, bordering on Yanshan mountain in the north, the Bohai sea in the south, and Liaoning province in the east. Since Shanhaiguan was a unique transportation hub in ancient times, it was also known as "the first pass of the Great Wall" [25]. As a representative section of the Great Wall of the Ming Dynasty, the Shanhaiguan Great Wall is historically valuable and is a significant site that has been protected at the national level since 1961. However, due to natural erosion and anthropogenic activities, the Shanhaiguan section of the Great Wall is significantly damaged (Fig. 1). The soil on the inside of the wall is loose, and the foundation of the wall has sunk into the ground, causing cracks in the wall [25]. Therefore, it is urgent to establish an effective largescale dynamic deformation monitoring system to support the sustainable conservation of the Shanhaiguan section of the Great Wall.

\section{Data}

A descending TerraSAR-X (TSX) multi-temporal Stripmap dataset (32 scenes) acquired from 2017 to 2019 was analyzed in this study. The ground spatial resolution of the SAR data was approximately $3 \mathrm{~m}$, and the central incidence angle was $39.2^{\circ}$. The coverage of the SAR dataset is illustrated in Fig. 2. The section of the SAR image covering the Shanhaiguan Great Wall was extracted from the larger image (yellow rectangle in Fig. 2) to facilitate data processing. The PSInSAR and SBAS interferometric configurations of the two datasets are shown in Fig. 3.

\section{Methodology and data processing}

Differential SAR interferometry (DInSAR) measures the displacement of the ground occurring between the acquisition intervals of SAR image pairs using the phase difference of the SAR signal in the line-of-sight direction (Fig. 4) [26]. Firstly, SAR image pairs are coregistrated using the amplitude correlation approach, resulting in a subpixel coregistration accuracy (i.e., better than $1 / 10$ of a pixel) to avoid the decorrelation of interferograms. Subsequently, the differential phase calculation of the corregistered SAR images is performed as follows [27]:

$$
\begin{aligned}
& \Delta \varphi_{\text {Int }}=\operatorname{angle}\left(S L C_{1} * S L C_{2}\right)=\varphi_{m}-\varphi_{s} \\
& \Delta \varphi_{D-I n t}=\Delta \varphi_{\text {Int }}-\varphi_{\text {Topo_simu }}
\end{aligned}
$$

where $S L C_{m}$ and $S L C_{s}$ denote the signals of the master and slave images, respectively; $\varphi_{m}$ and $\varphi_{s}$ denote the phases of the master and slave images, respectively; $\varphi_{\text {Topo_simu }}$ denotes the simulated height-related phase. angle $(\cdot)$ is the angle of the complex data; $(*)$ is the conjugate multiplication of the complex data. Since the 


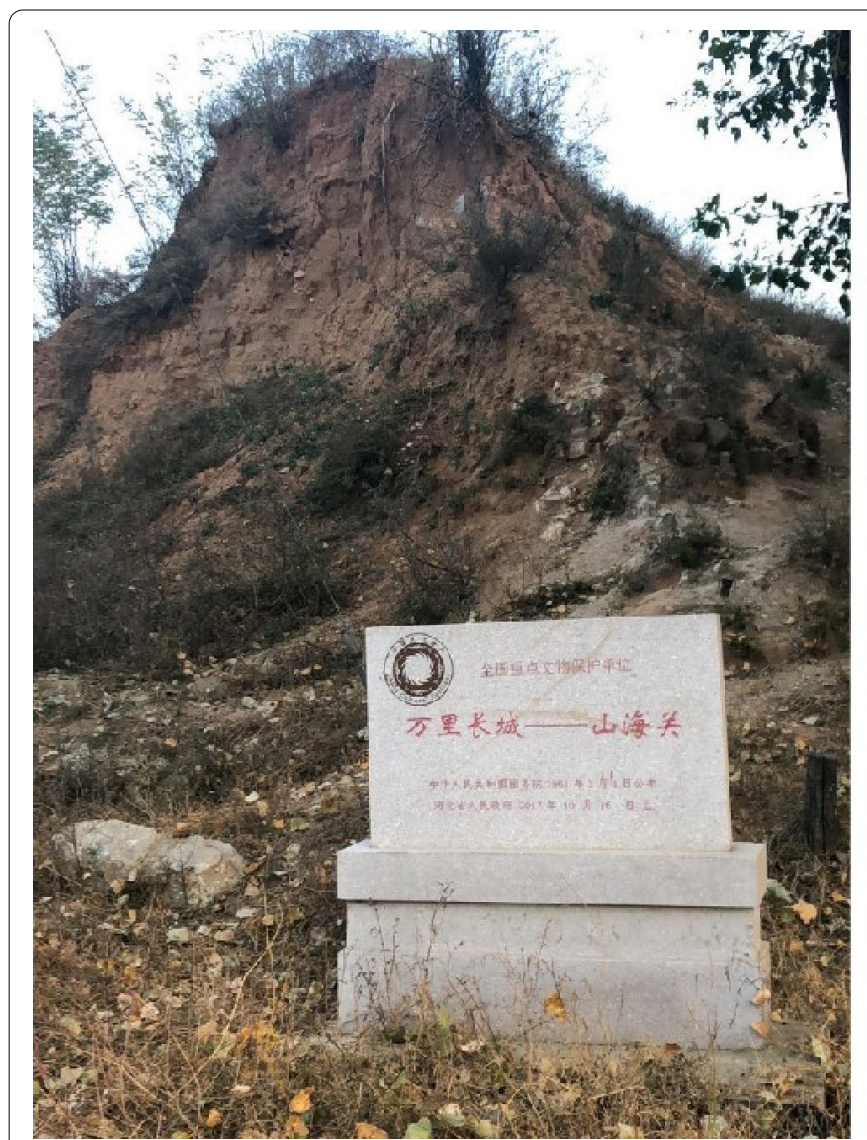

Fig. 1 On-site photos of the Shanhaiguan section of the Great Wall
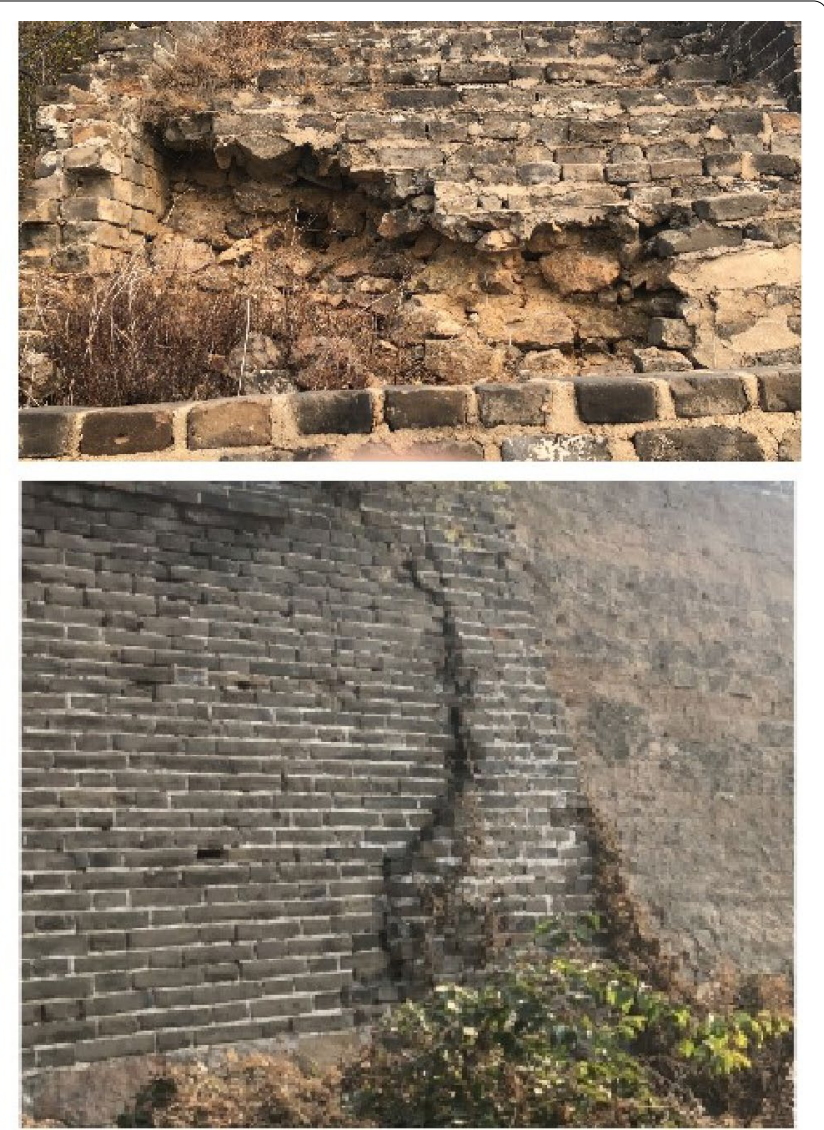

displacement-related phase changes linearly with the ground motion, the displacement can be calculated from the differential phase and the known SAR observation geometry.

Since the wavelength of the X-band radar signal is only a few centimeters $(3.1 \mathrm{~cm}$ for TerraSAR-X), the DInSAR measurement approach should be sensitive to changes in the ground object, and millimeter accuracy can be reached theoretically. Due to the effect of spatiotemporal decorrelation and the atmospheric phase disturbance [28], the precision of DInSAR measurements can decline to centimeters in practice.

\section{PSInSAR}

A novel InSAR technique referred to as PSInSAR was proposed [29] to overcome the limitations of temporal and geometrical decorrelation and separate the displacement phase from other phase components of the differential interferogram (e.g., atmospheric phase). PSInSAR has the potential for millimeter-level ground motion mapping [15].
The first step of the PSInSAR procedure is the PS candidate selection. Points coherent over long time intervals are selected by indicators, such as the amplitude dispersion [30]. For the ith point, the phase components can be simplified as follows:

$$
\left(\Delta \varphi_{D_{-} I n t}\right)_{i}=\left(\varphi_{\text {ele }}\right)_{i}+\left(\varphi_{\text {def }}\right)_{i}+\left(\varphi_{\text {APS }}\right)_{i}+\left(\varphi_{\text {dec }}\right)_{i}
$$

where $\varphi_{m}$ denotes the elevation phase, $\varphi_{\text {def }}$ is the deformation phase, $\varphi_{\text {APS }}$ denotes the atmospheric phase, and $\varphi_{d e c}$ is the noise phase. Subsequently, a triangulated irregular network is constructed to connect adjacent points. The phase of the adjacent points is subtracted to mitigate atmospheric and other noise. Subsequently, a periodogram or solution space search method is used to estimate the unknown parameters of the motion and residual height between adjacent points, followed by a network adjustment to reconstruct the absolute parameters of each PS point. Finally, a spatiotemporal filter is used to remove the atmospheric phase signals since they are highly correlated in space and weakly in time [29]. 


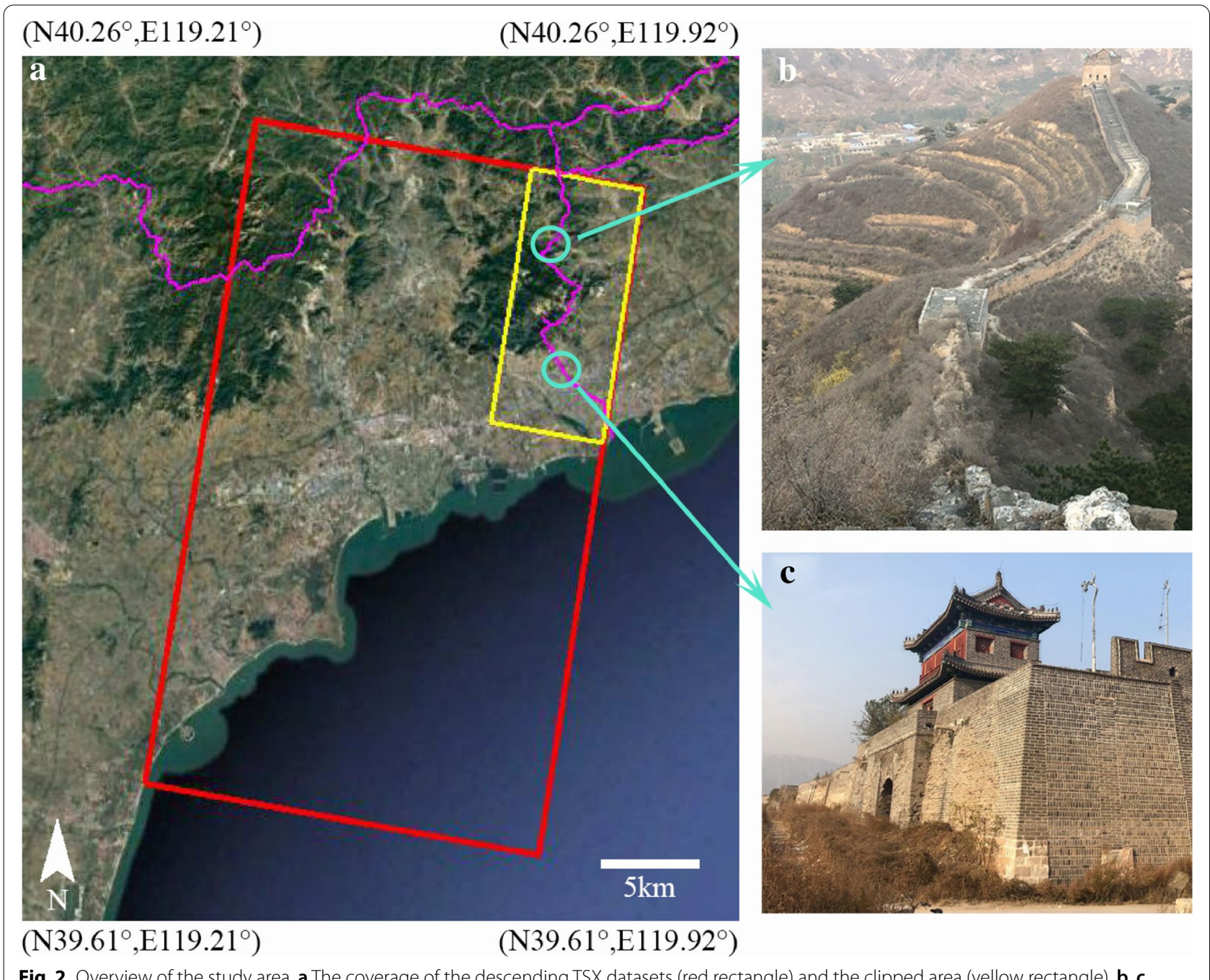

Fig. 2 Overview of the study area. a The coverage of the descending TSX datasets (red rectangle) and the clipped area (yellow rectangle). b, c Photos of two typical landscapes within the study area. Background image: Google Map
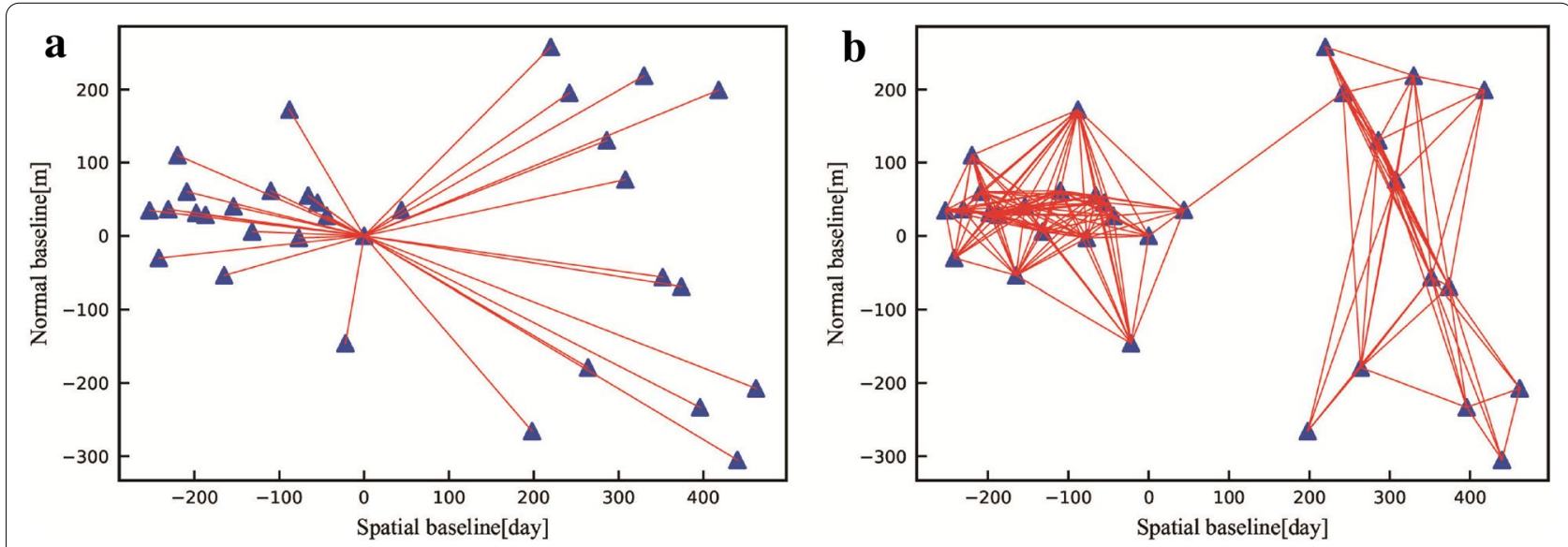

Fig. 3 The temporal and normal baselines of the TSX images. $\mathbf{a}$ and $\mathbf{b}$ are the baselines used in PSInSAR and SBAS processing, respectively 


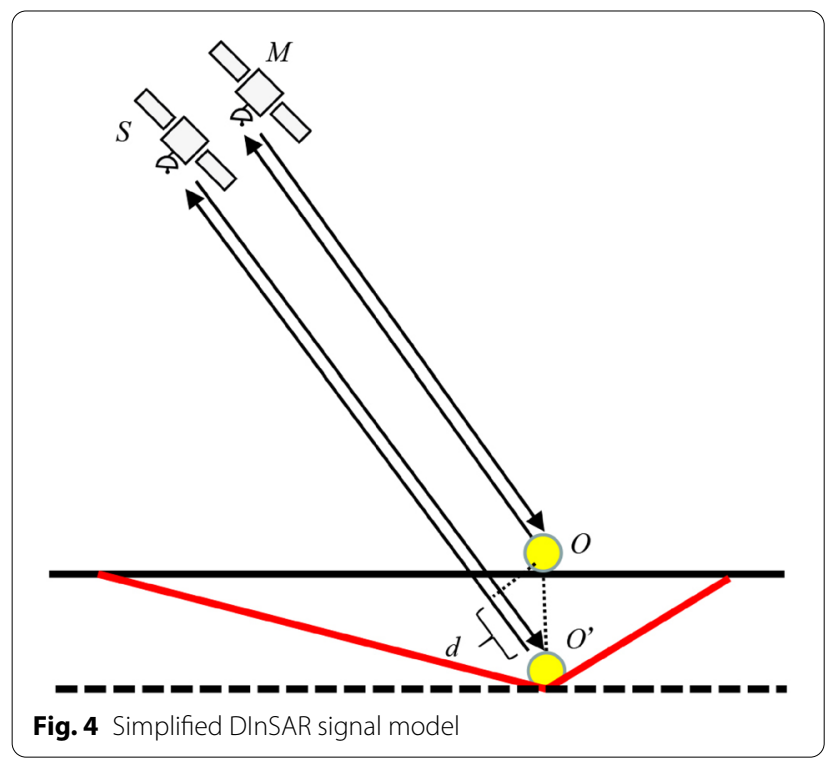

The PSInSAR approach utilizes a strict candidate point selection threshold; only ground features such as buildings, bridges, and other structures that remain coherent over time can be retrieved. With an appropriate SAR dataset and careful data processing, the PSInSAR approach can reach submillimeter accuracy $[15,16]$. However, a fixed PSInSAR threshold may cause a low density of candidate points in the research region, especially in vegetated areas where the landscape changes quickly over time. The low density of the PS points can affect the robustness of the PSInSAR algorithm by changing the structure and density of the network during PSInSARnSAR processing.

\section{SBAS}

The SBAS approach [31] is a creative MTInSAR technique. Unlike PSInSAR, SBAS utilizes a combination of image pairs with a small temporal and spatial baseline to maintain the temporal and spatial correlation. This combination increases the temporal sampling rate and improves the coherence of the interferograms, resulting in more reliable points in the final deformation maps.

In the SBAS technique, SAR image pairs with a small temporal and spatial baseline between the orbits were selected to generate the interferograms, preserving the temporal and spatial coherence characteristics of the interferograms [32]. Subsequently, multilooking [33] and filtering were used to decrease the noise and increase the image coherence. Then, phase unwrapping was performed using the minimum-cost flow algorithm [34] to obtain the relative phase from the original modulo- $2 \pi$ differential phase. The relationship between the motionrelated phase and ground displacement is linear after phase unwrapping. Due to the potential disconnection between different subsets, singular value decomposition (SVD) was used to reconstruct the time-series deformation of the coherent points. The final step of SBAS is spatiotemporal filtering, which utilizes the temporal and spatial statistics of the data to identify undesired atmospheric artifacts [32]:

$$
B v=\Delta \phi
$$

where B is the matrix after SVD; $\Delta \phi$ denotes the phase of the differential interferograms; $v$ denotes the deformation velocity to be solved. The SBAS method provides a higher spatial density of the deformation measurement points than the PSInSAR approach and has better adaptability in non-urban areas. However, the averaging processes (multilooking and filtering) may decrease the accuracy of the SBAS method. In addition, the accuracy of the SBAS method is highly sensitive to the accuracy of the phase unwrapping algorithm, whose robustness may not be high in vegetated areas that exhibit temporal decorrelation or in mountain areas with digital elevation model (DEM) errors.

\section{Cross-validation}

The accuracy of the PSInSAR and SBAS deformation measurements must be validated prior to the analysis of the deformation map (Fig. 5). Due to the lack of geodetic data, such as GPS data or precise leveling, cross-validation between the PSInSAR and SBAS approaches was used [6].

First, two histograms involving all the points from the PSInSAR and SBAS deformation maps were generated (Fig. 6). The histogram shapes were similar to a Gaussian distribution, indicating that the research area was relatively stable. The mean deformation velocity values were -0.44 and $-0.73 \mathrm{~mm} /$ year for PSInSAR and SBAS, respectively, and the standard deviations of the two datasets were 5.09 and $4.06 \mathrm{~mm} /$ year, respectively. The high consistency of the means and standard deviations between the two histograms indicates the consistency between the PSInSAR and SBAS deformation results. Note that the histogram derived from the SBAS approach is smoother than that derived from the PSInSAR; this result is attributed to the multilooking and filtering steps during SBAS processing. In order to verify the consistency of the PSInSAR and SBAS deformation products in detail, the longitudinal profile of the motion velocity obtained from the PSInSAR and SBAS approaches was extracted and cross-validated (Fig. 7). Consistent motion with deviations from 0 to $6.0 \mathrm{~mm}$ was observed. 

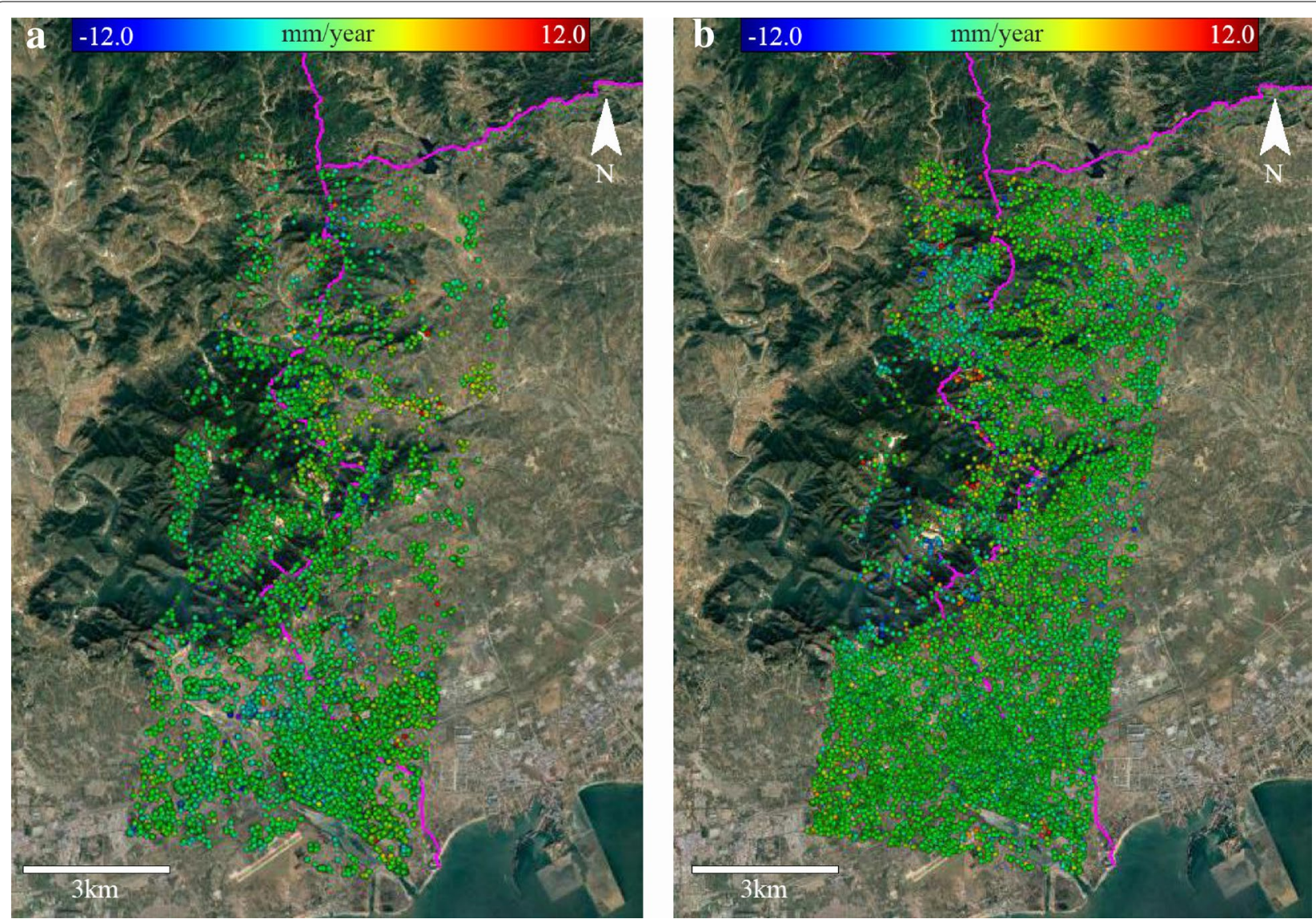

Fig. 5 Motion velocity maps of the Shanhaiguan Great Wall derived from a PSInSAR and b SBAS measurements. Background image: Google Map
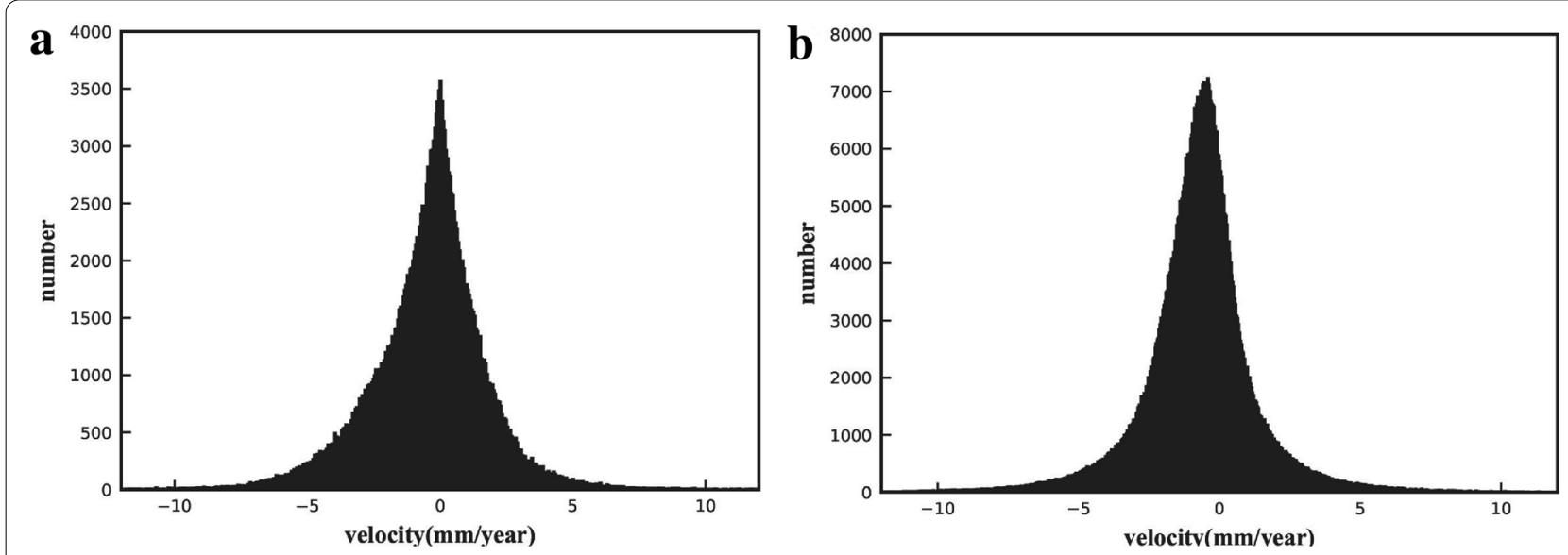

Fig. 6 Motion velocity distribution of the PSInSAR and SBAS measurements 


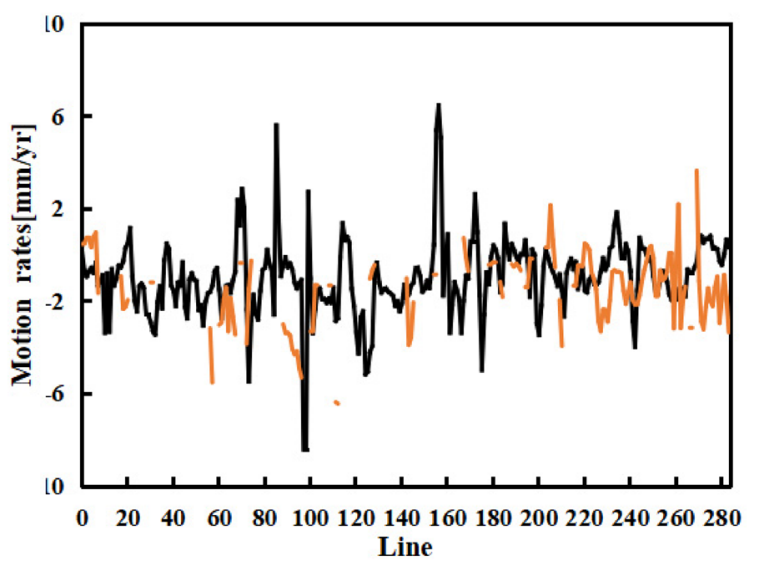

Fig. 7 Comparison of deformation velocity obtained from the SBAS and PSInSAR approaches in the longitudinal profiles

\section{Results and interpretation}

A 500-m buffer around the Great Wall was generated to evaluate the stability of the Shanhaiguan section. A threshold of $4.6 \mathrm{~mm}$ /year (the average standard deviation of the PSInSAR and SBAS motion velocity) was used to classify the deformation results into stable and unstable areas (Fig. 8a, b). The results indicated that the stability maps obtained from the PSInSAR and SBAS methods were generally consistent. The southeast portion of the corridor exhibited stability during the SAR monitoring period, whereas local deformation anomalies were detected in the central and northern sections of the corridor in the mountainous area.

A statistical analysis of the stability maps showed that the unstable pixels identified by the PSInSAR and SBAS approaches accounted for $1.10 \%$ and $5.48 \%$, respectively, of all pixels in the corridor. The difference between the PSInSAR and SBAS results was attributed to the different densities of the deformation monitoring points. High deformation was mostly observed in the mountainous areas, where the number of PS candidates was relatively low, and local deformation anomalies along the corridor may be omitted. In contrast, the SBAS results were better in the mountainous areas than the PSInSAR results, and more sites with deformation anomalies were detected. Pixels with ground motion information in the SBAS results accounted for $43.1 \%$ of all pixels in the corridor, which was twice the proportion of the PSInSAR results (19.5\%).

The deformation of the Shanhaiguan section of the Great Wall was further analyzed by integrating slope data (Fig. 8c). The slope of the unstable areas was higher than the average value in the PSInSAR and SBAS stability maps. The average slope value of the entire corridor was 15.6 degree, and the average slope values in the unstable areas of the PSInSAR and SBAS results were 16.2 degree and 19.2 degree, respectively. Thus, there is a positive correlation between the slope and stability of the area. Note that the average slope of the unstable points obtained from the PSInSAR is smaller than that of the SBAS method, which was attributed to the insufficient observation points in the mountain area for the PSInSAR approach.

A field investigation of the Shanhaiguan section was conducted. Although the plain section of the corridor passes through Shanhaiguan city, the local government has preserved the original appearance of the Great Wall and its surrounding environment during urban construction; thus, this section of the Great Wall has been less disturbed by anthropogenic activities. The slope is relatively steep in the mountain section of the corridor, and rock falls are likely events due to long-term weathering. Thus, local instability occurs in this area (Fig. 8d).

\section{Discussion}

As a large defensive architecture, the Great Wall has been built in mountainous areas, where the radar phase suffers from temporal decorrelation due to vegetation growth and elevation errors introduced by inaccurate DEM data. The decorrelation and DEM errors introduce noise into the radar phase signal, posing challenges to motion-related signal separation. This section focuses on the analysis of the factors that may affect the robustness of the PSInSAR and SBAS results during data processing.

\section{Analysis of PSInSAR deformation products}

It is difficult to acquire robust deformation results in mountainous areas in PSInSAR processing due to the limitation of the density of candidate points. Different combinations of the distance threshold (the lines connecting two PS candidates with distances exceeding the threshold were deleted) and ensemble coherence [29] were tested and compared (Fig. 9), and the corresponding histograms showing the motion velotity distribution of the PSInSAR measurements were provided as Fig. 10. The distance thresholds were $300 \mathrm{~m}, 700 \mathrm{~m}$, and $1000 \mathrm{~m}$, and the ensemble coherence thresholds were 0.68 and 0.7 . The optimal deformation results were obtained for an ensemble coherence of 0.68 and a distance threshold of $1000 \mathrm{~m}$ (Fig. 9a). This parameter combination provided enough candidate points in the northeast of the research area to minimize the error caused by the unstable network construction during the PSInSAR process. In the other threshold combinations, an increase in the ensemble coherence resulted 

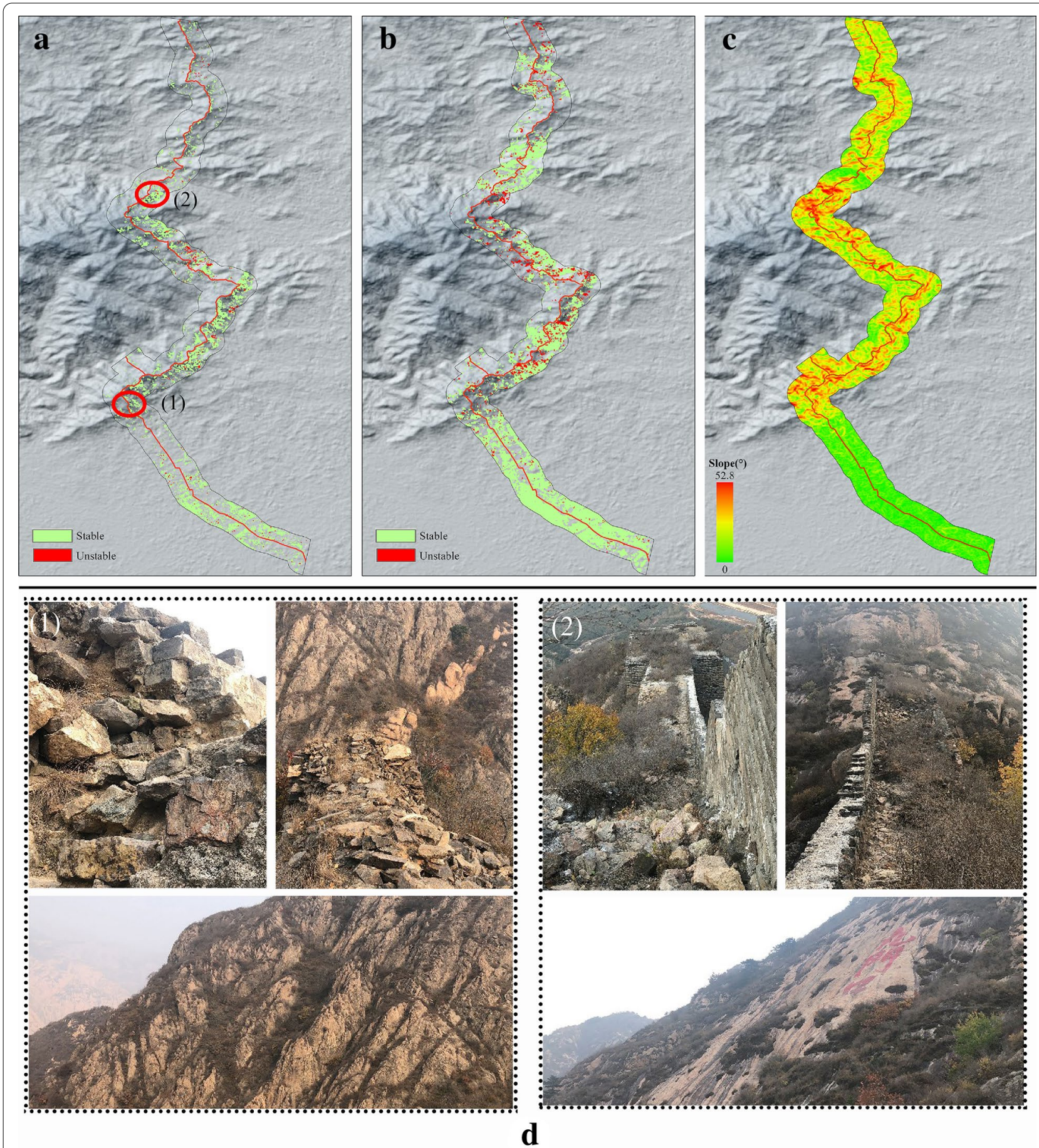

Fig. 8 Stability map of the Shanhaigan Great Wall. a-b Binary classification map of the stable and unstable areas of the Shanhaigan Great Wall derived from the PSInSAR and SBAS approaches, respectively. $\mathbf{c}$ The slope of the corridor along the Shanhaiguan Great Wall. d Photos of typical landscapes of two field survey sites (outlined in red in a)

in a low density of the PS candidates and an unstable network, causing deformation errors in the northeast of the research area (Fig. 9c). A decrease in the ensemble coherence reduced the quality of the PS points and the accuracy of the PSInSAR result (Fig. 9b). A decrease in the distance threshold resulted in a low number of PS, resulting in an unstable network and causing local deformation errors (Fig. 9d). 
(See figure on next page.)

Fig. 9 Motion velocity maps of the Shanhaiguan Great Wall derived from the PSInSAR approach using different thresholds. $\mathbf{a}$ Distance $=1000 \mathrm{~m}$ and ensemble coherence $=0.68$. $\mathbf{b}$ Distance $=1000 \mathrm{~m}$ and ensemble coherence $=0.7$. $\mathbf{c}$ Distance $=700 \mathrm{~m}$ and ensemble coherence $=0.68$. $\mathbf{d}$ Distance $=300 \mathrm{~m}$ and ensemble coherence $=0.7$. Background image: Google Map

\section{Analysis of SBAS deformation products}

In the SBAS approach, the accuracy of the deformation products is affected by the phase unwrapping error. In this study, two sets of SBAS results with similar baseline combinations were compared (Fig. 11). Figure 12b shows the temporal and normal baselines of adding two differential interferograms to those shown in Fig. 12a during SBAS processing. The temporal baselines of the two interferograms were 220 days and 176 days, and the normal baselines of the interferograms were $-119.8 \mathrm{~m}$ and $222.6 \mathrm{~m}$. Due to the relatively large temporal and normal baselines, phase decorrelations were observed in the two pairs of interferograms, posing challenges in the phase unwrapping (Fig. 12c). Thus, significant errors were observed in the final deformation product. Therefore, the accuracy of phase unwrapping should be improved in the SBAS process to minimize the errors.

\section{Conclusion and prospect}

There is a lack of performance evaluations in existing InSAR heritage deformation monitoring applications. Thus, in this study, deformation products were generated using high-resolution TSX data and PSInSAR and SBAS approaches to compare the suitability of the two approaches for deformation monitoring of the Shanhaiguan section of the Great Wall.

The results of the comparative case study indicate the following: (1) the Shanhaiguan section of the Great Wall is relatively stable and has not been adversely affected by anthropogenic activities in urban areas during the SAR monitoring period. In contrast, local deformation anomalies that were likely caused by rock falls were detected in the mountainous areas. (2) The complex mountain terrain poses challenges to the use of the PSInSAR and
SBAS methods. PSInSAR suffers from an insufficient density of deformation points in mountainous areas, and the SBAS approach is limited by the accuracy of the phase unwrapping process.

This study revealed the potential of InSAR techniques for stability monitoring along the landscape corridor of the Great Wall. However, there are still several limitations remain to be overcome. For instance, this study focuses on the surface deformation monitoring of the landscape due to the spatial resolution limitation of the applied SAR data; and the applied PSInSAR and SBAS approaches are not optimized for the deformation monitoring of the Great Wall in this study. Consequently, as future studies, we will focus on following issues: (1) the scattering mechanism of the SAR echo signal will be analyzed to increase the density of InSAR measurements in mountainous areas, enabling the detection of more local anomalies of the heritage site; (2) adaptable InSAR approaches will be developed for the deformation monitoring of heritage site in complicated cultural scenarios. For instance, the temporarily coherent points (TCP) algorithm [35] can be exploited to enhance the robustness of the PSInSAR analysis, and the pseudo-baseline combination method [36] can be integrated with the SBAS method to mitigate the inaccurate height estimation; (3) the baseline criteria for the structural instability monitoring and health diagnosis of architectural heritage can be researched when high resolution SAR images are available; (4) a comparison between InSAR and other digital heritage methods (e.g., LiDAR) can be implemented to investigate the strengths and weaknesses of InSAR for the deformation monitoring of culture heritages. 

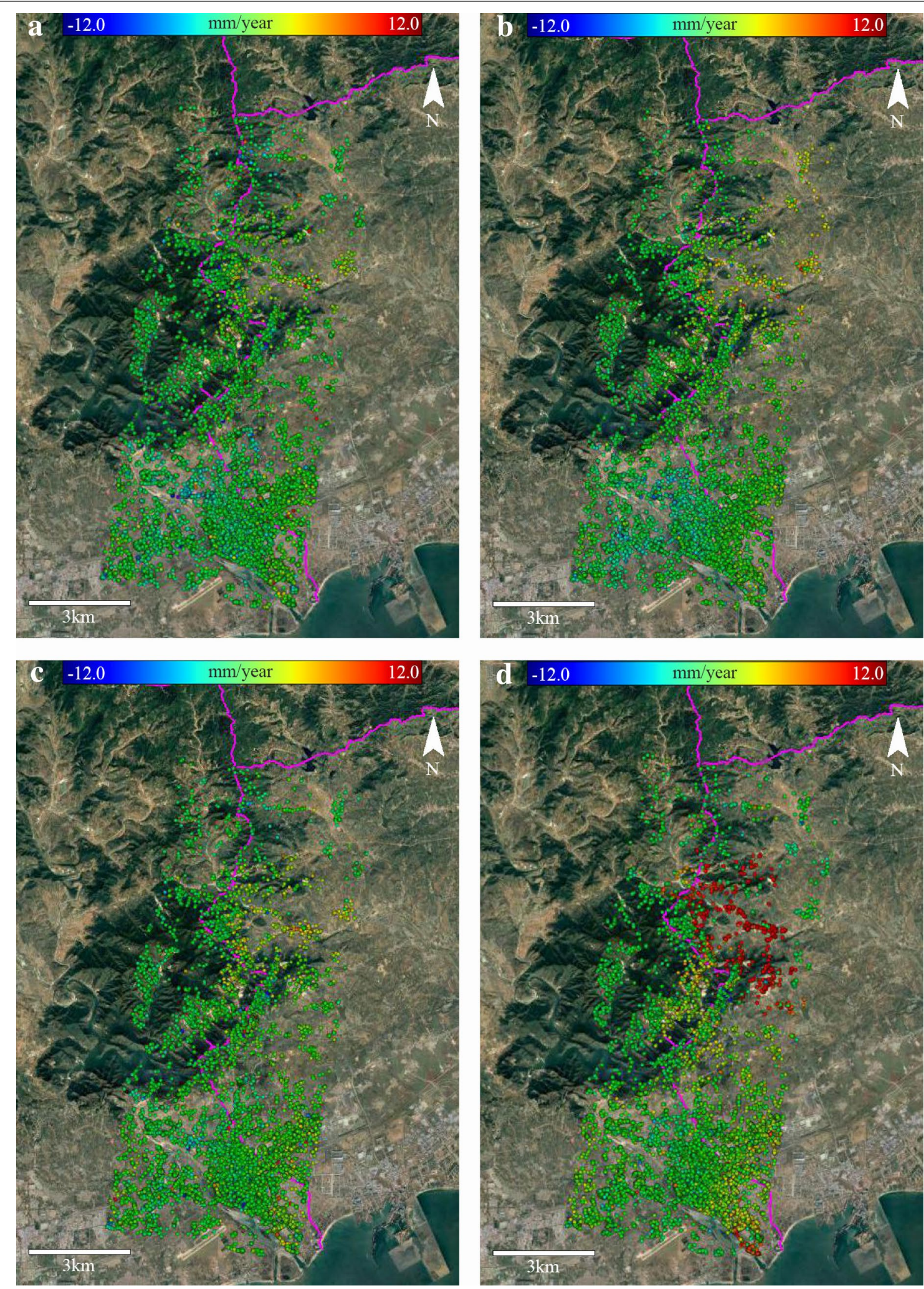

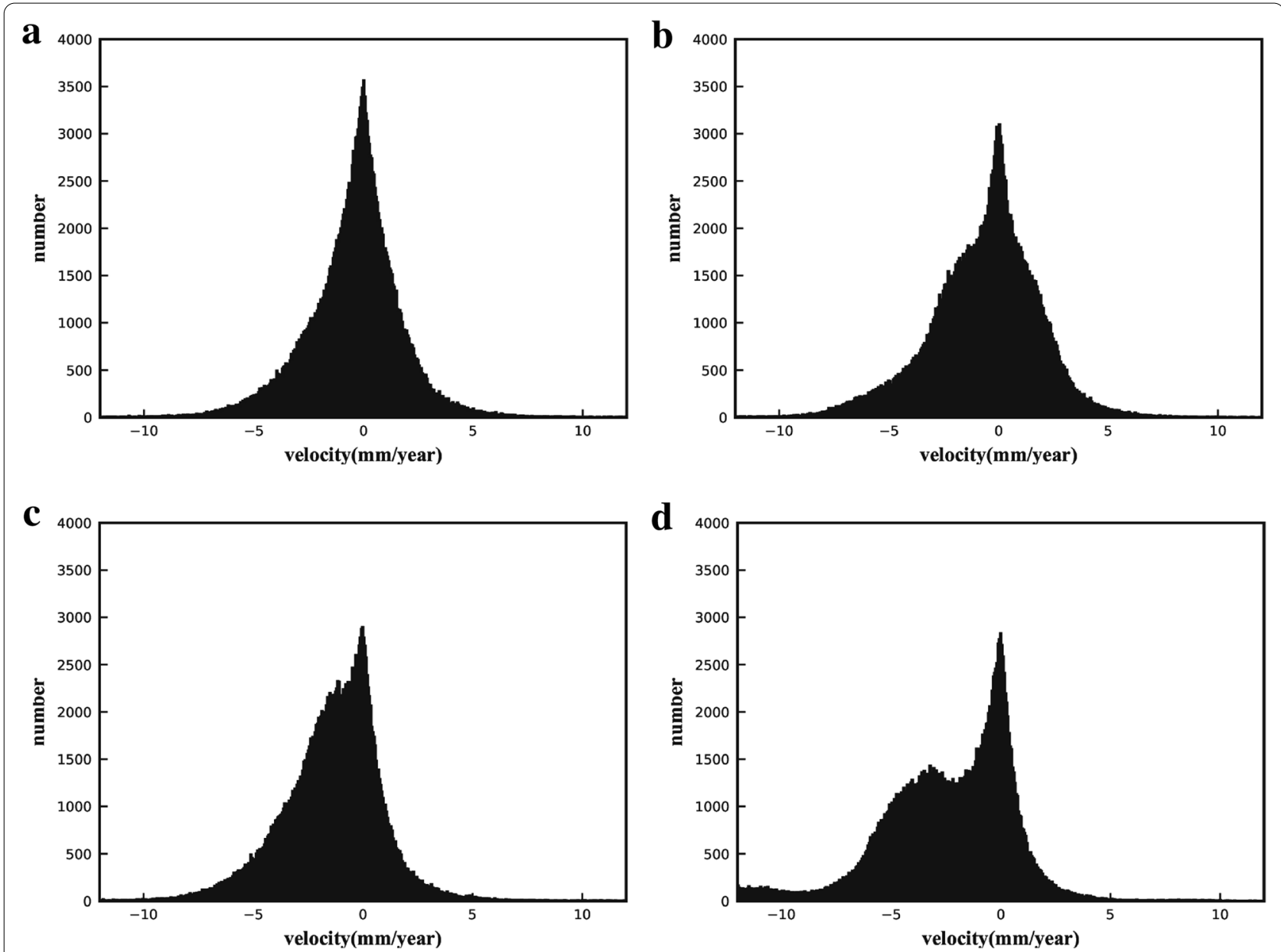

Fig. 10 Motion velocity distribution of the PSInSAR measurements for different thresholds. a Distance $=1000 \mathrm{~m}$ and ensemble coherence $=0.68$. b Distance $=1000 \mathrm{~m}$ and ensemble coherence $=0.7$. $\mathbf{c}$ Distance $=700 \mathrm{~m}$ and ensemble coherence $=0.68$. $\mathbf{d}$ Distance $=300 \mathrm{~m}$ and ensemble coherence $=0.7$ 

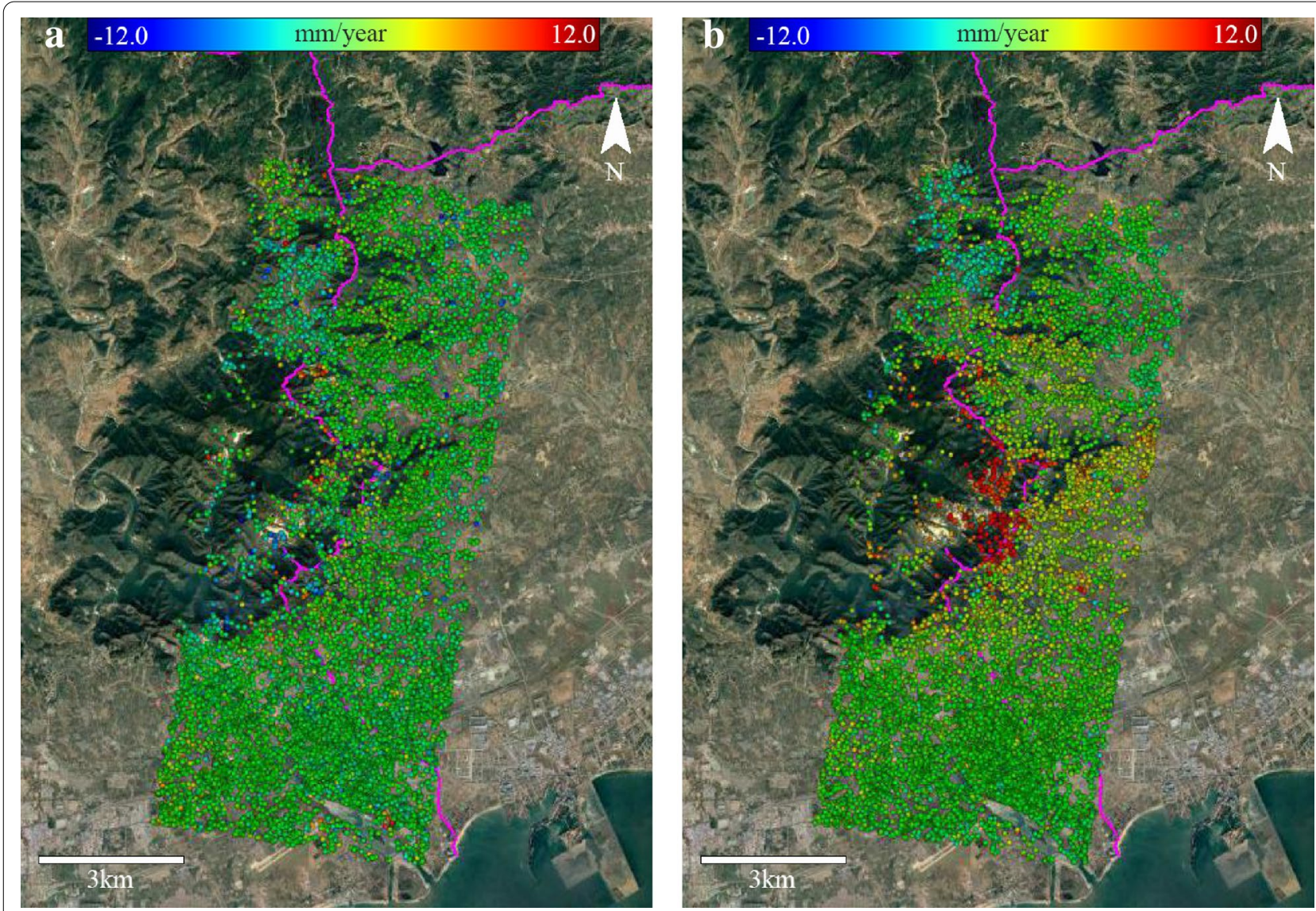

Fig. 11 Motion velocity maps of the Shanhaiguan Great Wall derived from the SBAS approach for different combinations of baselines. Background image: Google Map 

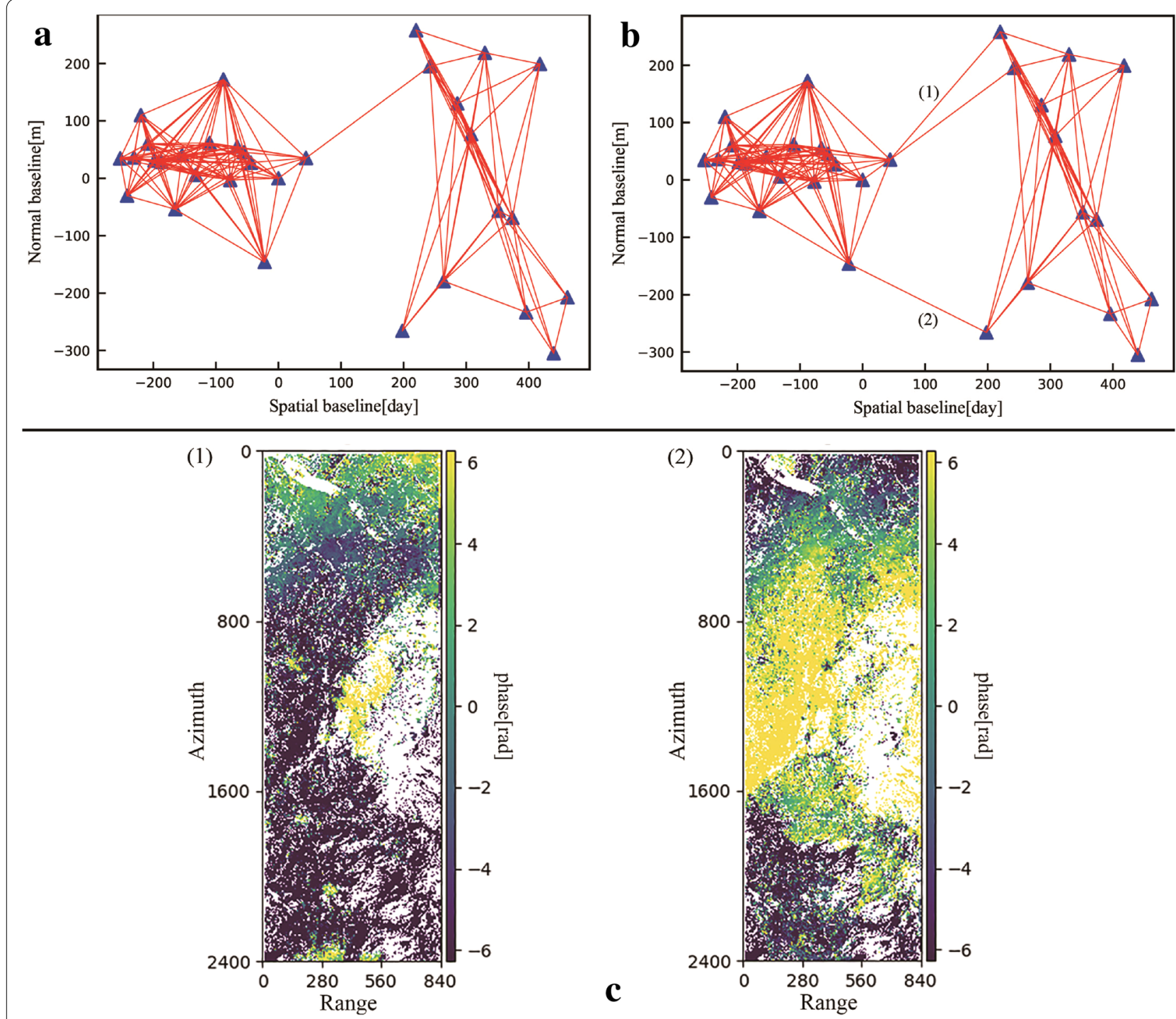

Fig. 12 a-b Temporal and normal baselines used for the SBAS inversion. c Interferometry pairs with unwrapping errors (the color bar has a range of $\pm 2 \pi$ ) 


\section{Abbreviations}

SAR: Synthetic aperture radar; InSAR: SAR interferometry; DInSAR: Differential SAR interferometry; MTInSAR: Multi-temporal SAR interferometry; PSInSAR: Persistent scatterer SAR interferometry; SBAS: Small baseline subset; TSX: TerraSAR-X; SVD: Singular value decomposition; DEM: Digital elevation model; TCP: Temporarily coherent points.

\section{Acknowledgements}

The TerraSAR-X data used in this study were provided by the Deutsches Zentrum für Luft- und Raumfahrt (DLR) under the AO TSX-Archive project (CAL3304). The comments and criticisms provided by the anonymous reviewers are appreciated.

\section{Authors' contributions}

$H X$ was responsible for the SAR data processing and drafting of the manuscript. FC was responsible for the study design and the review of the manuscript. WZ was responsible for the SAR data collection and InSAR result interpretation. All authors read and approved the final manuscript.

\section{Funding}

This work was jointly supported by the National Natural Science Foundation of China (NSFC) [Grant No. 41771489] and the National Key Research and Development Program of China [No. 2017YFE0134400].

\section{Availability of data and materials}

All data generated or analyzed during this study are included in this published article.

\section{Declarations}

\section{Competing interests}

The authors declare that they have no competing interests.

\section{Author details}

${ }^{1}$ Key Laboratory of Digital Earth Science, Aerospace Information Research Institute, Chinese Academy of Sciences, Beijing 100094, China. ${ }^{2}$ International Centre on Space Technologies for Natural and Cultural Heritage (HIST) under the Auspices of UNESCO, Beijing 100094, China. ${ }^{3}$ University of Chinese Academy of Sciences, Beijing 101408, China.

Received: 5 March 2021 Accepted: 4 May 2021

Published online: 11 June 2021

\section{References}

1. Su M, Wall G. Global-local relationships and governance issues at the Great Wall world heritage site. China J Sustain Tour. 2012;20:1067-86.

2. Huang $X$. China's experience of protecting the Great Wall: the giant linear cultural heritage. J Herit Manag. 2016;1:126-47.

3. Liu Y, Gao J, Yang Y. A Holistic approach towards assessment of severity of land degradation along the Great Wall in northern Shaanxi province. China Environ Monit Assess. 2003;82:187-202.

4. Deng F, Zhu X, Li X, Li M. 3D digitisation of large-scale unstructured Great Wall heritage sites by a small unmanned helicopter. Remote Sens. 2017;9:423.

5. Hua W, Qiao Y, Hou M. The Great Wall 3D documentation and application based on multisource data fusion-a case study of no.15 enemy tower of the new Guangwu Great Wall. Int Arch Photogramm Remote Sens Spat Inf Sci. 2020;43:176-81.

6. Chen F, Zhou W, Xu H, Parcharidis I, Lin H, Fang C. Space technology facilitates the preventive monitoring and preservation of the Great Wall of the Ming dynasty: a comparative study of the Qingtongxia and Zhangjiakou sections in China. IEEE J Sel Top Appl Earth Obs Remote Sens. 2020;13:5719-29.

7. Bitelli G, Dubbini M, Zanutta A. Terrestrial laser scanning and digital photogrammetry techniques to monitor landslide bodies. Int Arch Photogramm Remote Sens Spat Inf Sci. 2004;35:246-51.
8. Pesci A, Casula G, Boschi E. Laser scanning the Garisenda and Asinelli towers in Bologna (Italy): detailed deformation patterns of two ancient leaning buildings. J Cult Herit. 2011;12:117-27.

9. Garziera R, Amabili M, Collini L. Structural health monitoring techniques for historical buildings. In: Proceedings of the IV Pan-American Conference for non-destructive testing, Buenos Aires, Argentina. 2007; pp. 1-12.

10. Sigurdardottir D, Glisic B. On-site validation of fiber-optic methods for structural health monitoring: Streicker bridge. J Civ Struct Health Monit. 2015;5:529-49.

11. Lasaponara R, Leucci G, Masini N, Persico R, Scardozzi G. Towards an operative use of remote sensing for exploring the past using satellite data: The case study of Hierapolis (Turkey). Remote Sens Environ. 2016;174:148-64.

12. Chen F, Guo H, Ma P, et al. Radar interferometry offers new insights into threats to the angkor site. Sci Adv. 2017;3:e1601284.

13. Xiao W, Mills J, Guidi G, et al. Geoinformatics for the conservation and promotion of cultural heritage in support of the UN sustainable development goals. ISPRS J Photogramm Remote Sens. 2018;142:389-406.

14. Casu F, Manzo M, Lanari R. A quantitative assessment of the SBAS algorithm performance for surface deformation retrieval from DInSAR data. Remote Sens Environ. 2006;102:195-210.

15. Ferretti A, Savio G, Barzaghi R, et al. Submillimeter accuracy of InSAR time series: experimental validation. IEEE Trans Geosci Remote Sens. 2007:45:1142-53.

16. Raucoules D, Bourgine B, Michele $M$, et al. Validation and intercomparison of persistent scatterers interferometry: PSInSARc4 project results. J Appl Geophy. 2009;68:335-47.

17. Horst T, Rutten M, Giesen N, et al. Monitoring land subsidence in Yanggon, Myanmar using Sentinel-1 persistent scatterer interferometry and assessment of driving mechanisms. Remote Sens Environ. 2018:217:101-10.

18. Milillo P, Perissin D, Salzer J, et al. Monitoring dam structural health from space: insights from novel InSAR techniques and multi-parametric modeling applied to the Pertusillo dam Basilicata, Italy. Int J Appl Earth Obs Geoinf. 2016;52:221-9.

19. Crosetto M, Monserrat O, Cuevas-Gonzalez M, et al. Measuring thermal expansion using $X$-band persistent scatterer interferometry. ISPRS J Photogramm Remote Sens. 2015;100:84-91.

20. Chang L, Dollevoet R, Hanssen R. Nationwide railway monitoring using satellite SAR interferometry. IEEE J Sel Top Appl Earth Obs Remote Sens. 2016;10:1-9.

21. Cigna F, Lasaponara R, Masini N, et al. Persistent scatterer interferometry processing of COSMO-SkyMed StripMap HIMAGE time series to depict deformation of the historic centre of Rome, Italy. Remote Sens. 2014;6:12593-618.

22. Parcharidis I, Foumelis M, Pavlopoulos K, et al. Ground deformation monitoring in cultural heritage areas by time series interferometry: the case of ancient Olympia site (western Greece). In: Proceedings of the ESA FRINGE Workshop. 2010; pp. 236-239.

23. Tapete D, Cigna F. Rapid mapping and deformation analysis over cultural heritage and rural sites based on persistent scatterer interferometry. Int J Geophys. 2012. https://doi.org/10.1155/2012/618609.

24. Themistocleous K, Cuca B, Agapiou A, et al. The protection of cultural heritage sites from geo-hazards: the PROTHEGO project. Cham: Springer; 2016.

25. Wang J, Fu C. Analysis on the city wall stability for Shanhaiguan section of the Great Wall. J Eng Geol. 2006;14:301-7.

26. Rosen P, Hensley S, Joughin I, et al. Synthetic aperture radar interferometry. Proc IEEE. 2002;88:333-82.

27. Crosetto M, Monserrat O, Cuevas-Gonzalez M, et al. Persistent scatterer interferometry: a review. ISPRS J Photogramm Remote Sens. 2016;115:78-89.

28. Ferretti A, Prati C, Rocca F. Permanent scatterers in SAR interferometry. IEEE Trans Geosci Remote Sens. 2001;39:8-20.

29. Ferretti A, Prati C, Rocca F. Nonlinear subsidence rate estimation using permanent scatterers in differential SAR interferometry. IEEE Trans Geosci Remote Sens. 2000;38:2202-12.

30. Ferretti A, Prati C, Rocca F. Analysis of permanent scatterers in SAR interferometry. In: Proceedings of the IGARSS. 2000; pp. 761-3. 
31. Berardino P, Fornaro G, Lanari R, et al. A new algorithm for surface deformation monitoring based on small baseline differential SAR interferograms. IEEE Trans Geosci Remote Sens. 2002;40:2375-83.

32. Lanari R, Casu F, Manzo M, et al. Application of the SBAS-DInSAR technique to fault creep: a case study of the Hayward fault, California. Remote Sens Environ. 2007;109:20-8.

33. Rosen P, Hensley S, Joughin I, et al. Synthetic aperture radar interferometry. Proc IEEE. 2000;88:333-76.

34. Costantini M, Rosen P. A generalized phase unwrapping approach for sparse data. In: Proceedings of the IGARSS. 1999; pp. 267-269.
35. Zhang L, Ding X, Lu Z. Modeling PSInSAR time series without phase unwrapping. IEEE Trans Geosci Remote Sens. 2011;49:547-56.

36. Zhang L, Jia $H$, Lu Z, Liang $H$, Ding X, Li X. Minimizing height effects in MTInSAR for deformation detection over built areas. IEEE Trans Geosci Remote Sens. 2019;57:9167-76.

\section{Publisher's Note}

Springer Nature remains neutral with regard to jurisdictional claims in published maps and institutional affiliations. 